\title{
Tensile properties of surface treated jute fibers under high environmental (ambient) temperatures
}

\author{
H. Katogi, K. Takemura \& R. Suzuki \\ Department of Mechanical Engineering, Kanagawa University, Japan
}

\begin{abstract}
In this study, the effects of alkaline and silane surface treatments on the tensile property of jute fiber were investigated. Surface treatments were conducted in distilled water with 1 to $5 \%$ concentrations at room temperature (RT) for two hours. A quasi-static tensile test was conducted. Environmental temperatures were RT, $50^{\circ} \mathrm{C}$ and $100^{\circ} \mathrm{C}$. As a result, the tensile strengths of $1 \%$ alkaline treated jute fiber were higher than those of virgin materials under all environmental temperatures. The Young's modulus of alkaline treated jute fiber under $50^{\circ} \mathrm{C}$ was higher than that of virgin material. The Young's modulus of alkaline treated jute fiber under $50^{\circ} \mathrm{C}$ was higher than that of virgin material. But, Young's modulus of alkaline treated jute fiber under $100^{\circ} \mathrm{C}$ almost did not change. It is thought that the tensile property of jute fiber was affected by the rate of cellulose in jute fiber after alkaline treatment. On the other hand, the tensile strength of silane treated jute fiber under RT was higher than that of virgin materials. Tensile strength of silane treated jute fiber under $50^{\circ} \mathrm{C}$ and $100^{\circ} \mathrm{C}$ almost did not change. Young's modulus of silane treated jute fiber under RT was higher than that of virgin material except for 5\% concentration. And, Young's modulus of silane treated jute fiber under $50^{\circ} \mathrm{C}$ was higher than that of virgin materials. But, Young's modulus of silane treated jute fiber under $100^{\circ} \mathrm{C}$ almost did not change. Therefore, the tensile property of jute fiber at less than $50^{\circ} \mathrm{C}$ was affected by silane treatment because of the coupling silanol group with a surface of jute fibers.

Keywords: natural fiber, alkaline treatment, silane treatment, tensile strength, Young's modulus.
\end{abstract}




\section{Introduction}

Green composite material, which is composed of biodegradable resin and natural fiber, has been studied about molding [1, 2] and mechanical properties [3-7] as alternative material to glass fiber reinforced plastic. Green composite material is used as a door trim ornament of interior parts [8]. But, the mechanical properties of green composite material as interior parts probably decrease due to temperature in a car. And the mechanical properties of green composites are low. So, many papers reported that mechanical properties of green composites were improved by surface treatment [9-11]. Katogi et al. [12] reported that flexural properties of green composites using alkaline and silane treated jute fiber were higher than that of virgin material under room temperature (RT). But, the flexural property of green composite material by using alkaline treated jute fiber was lower than that of virgin material under $50^{\circ} \mathrm{C}$.

There is a report on the tensile property of surface treated natural fiber as reinforcement. Reddy et al. [13] reported that tensile strength of borassus fruit fine fiber increased $66 \%$ by alkaline treatment. Sreekala et al. [14] reported that the tensile strength of oil palm fiber increased $10 \%$ by silane treatment. However, there are few reports about the tensile property of alkaline and silane treated natural fiber under environmental temperature.

In this study, the effects of alkaline and silane treatments on the tensile property of jute fiber under environmental temperature were investigated.

\section{Specimen}

Jute fiber was used as specimen. The jute fiber consists of elementally fibers. Figure 1 shows a schematic drawing of elementary fiber. Constituent materials

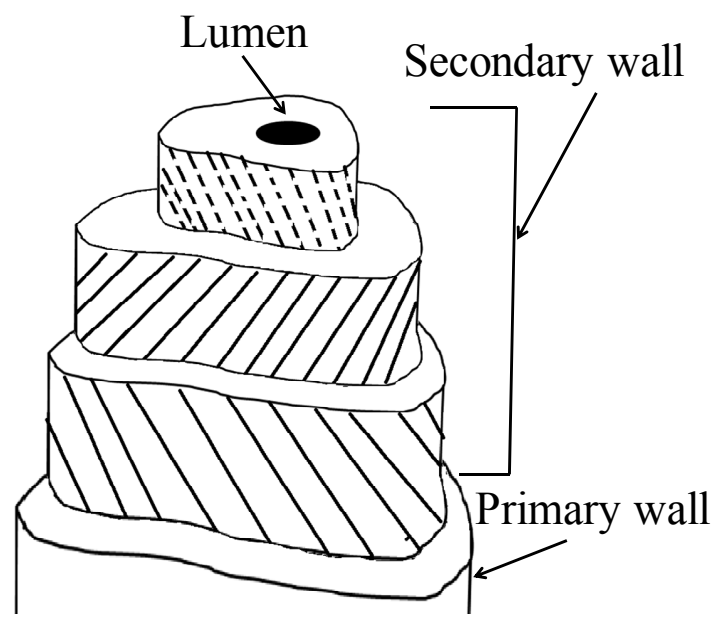

Figure 1: Schematic drawing of elementary fiber. 


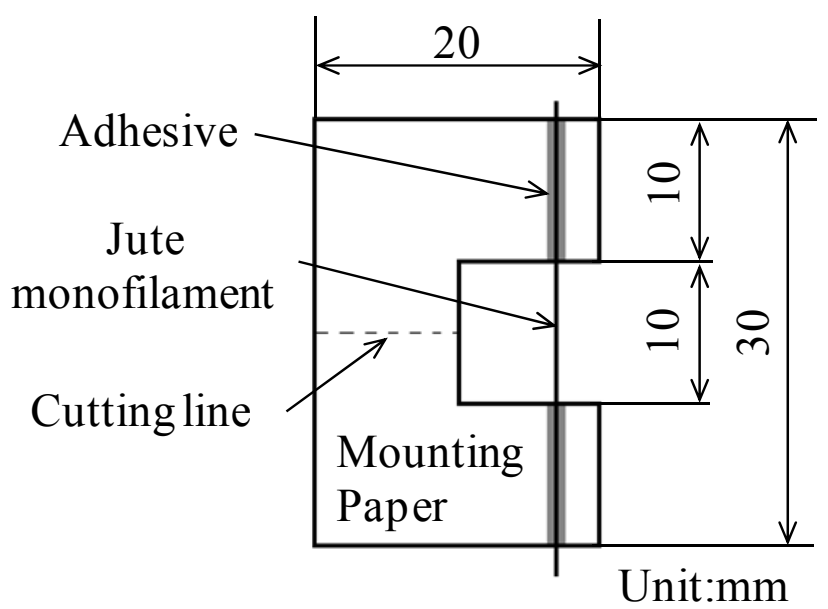

Figure 2: Schematic drawing of specimen.

of the elementary fiber are cellulose (63\%), lignin (14\%), hemicelluloses $(22 \%)$ and so on [15]. Jute fiber was treated by two surface treatments; alkaline treatment and silane treatment. Surface treatments were conducted in distilled water with $1 \%$ to $5 \%$ concentrations at room temperature (RT) for 2 hours. In case of alkaline treatment, jute fiber was washed in distilled water with $1 \%$ acetic acid for neutralization. After surface treatments, surface treated jute fiber was dried at $50^{\circ} \mathrm{C}$ for $24 \mathrm{hrs}$. Figure 2 shows a schematic drawing of the specimen.

\section{Testing method}

\subsection{Thermal mechanical analysis}

Thermal mechanical analysis (TMA) of surface treated jute fiber was conducted. The load was $0.1 \mathrm{~N}$. The environmental temperature was $30^{\circ} \mathrm{C}$ to $160^{\circ} \mathrm{C}$. The heating rate was $5^{\circ} \mathrm{C} / \mathrm{min}$. The number of specimens was five.

\subsection{Quasi-static tensile test}

Quasi-static tensile test was conducted. The crosshead speed was $1 \mathrm{~mm} / \mathrm{min}$. Environmental temperatures were $\mathrm{RT}, 50^{\circ} \mathrm{C}$ and $100^{\circ} \mathrm{C}$. The number of specimen was thirty. Cross sectional area at break point of jute fiber was estimated by elliptical approximation using photograph of specimen before quasi-static tensile test. The tensile strength was calculated by Weibull distribution. Young's modulus was calculated by using cross sectional area at seven points. 


\section{Results and discussion}

\subsection{Thermal mechanical analysis (TMA)}

Figure 3 shows typical strain-temperature curves of surface treated jute fiber. And table 1 shows the thermal property of surface treated jute fiber. Coefficients linear expansion of jute fiber at less than $140^{\circ} \mathrm{C}$ were decreased by surface treatments.

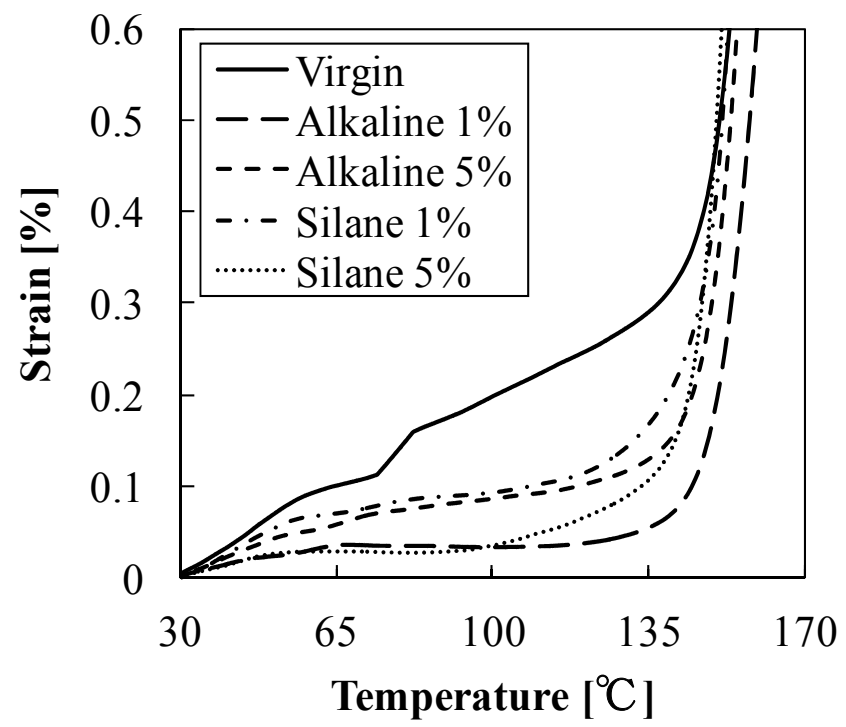

Figure 3: Typical strain-temperature curves of surface treated jute fibers.

Table 1: Thermal properties of surface treated jute fibers.

\begin{tabular}{|c|c|c|c|}
\hline & \multicolumn{2}{|c|}{$\begin{array}{c}\text { Coefficient of linear } \\
\text { expansion }\left[\times 10^{-4} /{ }^{\circ} \mathrm{C}\right]\end{array}$} & $\begin{array}{c}\text { Softening } \\
\text { point }\left[{ }^{\circ} \mathrm{C}\right]\end{array}$ \\
\cline { 2 - 3 } & $30^{\circ} \mathrm{C}-120^{\circ} \mathrm{C}$ & $120^{\circ} \mathrm{C}-140^{\circ} \mathrm{C}$ & \\
\hline Virgin & 1.89 & 3.68 & 140 \\
\hline Alkaline 1\% & 0.43 & 1.04 & 144 \\
\hline Alkaline 5\% & 0.72 & 1.56 & 141 \\
\hline Silane 1\% & 0.71 & 2.03 & 139 \\
\hline Silane 5\% & 0.60 & 1.70 & 140 \\
\hline
\end{tabular}




\subsection{Cross sectional area and tensile property}

Figure 4 shows the cross sectional area of jute fibers. The cross sectional area of jute fiber decreased with an increase of concentration of alkaline solution. On the other hand, cross sectional area of silane treated jute fiber increased a little. In case of alkaline treatment, hemicelluloses in jute fiber dissolved [15]. In the case of silane treatment, fiber surface was coupled with silanol group [16]. Therefore, the cross sectional area of jute fiber can be affected by both surface treatments.

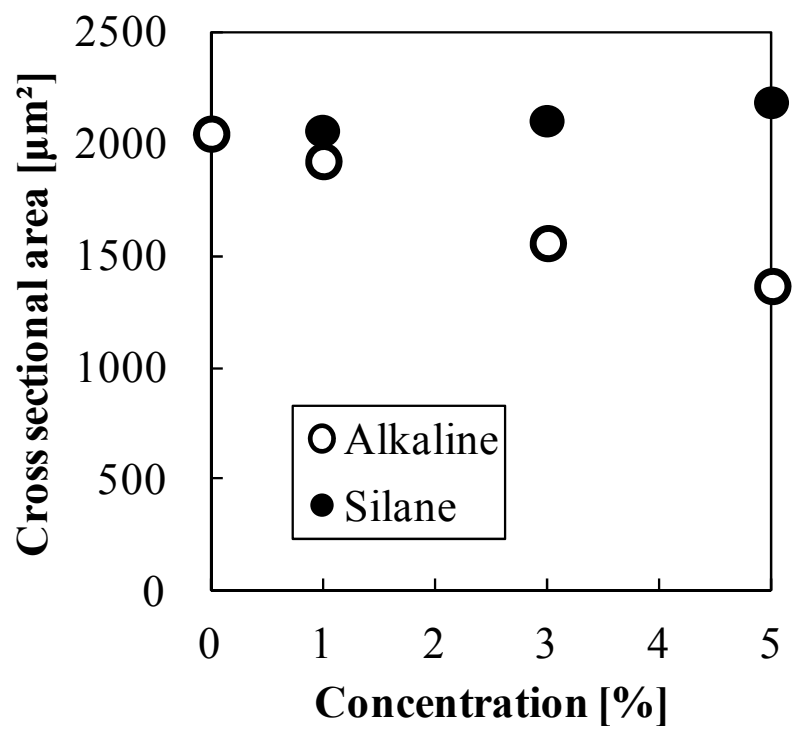

Figure 4: Effect of surface treatment on cross sectional area of jute fiber.

Figure 5 shows the tensile properties of alkaline treated jute fibers. The tensile strength of alkaline treated jute fiber showed the maximum value in $1 \%$ concentration under all environmental temperatures. Young's modulus of alkaline treated jute fiber under RT showed the maximum value in $1 \%$ concentration. The Young's modulus of alkaline treated jute fiber under $50^{\circ} \mathrm{C}$ was higher than that of virgin material. But, Young's modulus of alkaline treated jute fiber under $100^{\circ} \mathrm{C}$ almost did not change. The rate of cellulose in jute fiber was probably increased by decrease of cross sectional area of jute fiber after alkaline treatment. Therefore, it is thought that the tensile property of jute fiber at less than $50^{\circ} \mathrm{C}$ was affected by alkaline treatment.

Figure 6 shows the tensile property of silane treated jute fibers. The tensile strength of silane treated jute fiber under RT was higher than that of virgin materials. The tensile strength of silane treated jute fiber under $50^{\circ} \mathrm{C}$ and $100^{\circ} \mathrm{C}$ almost did not change. Young's modulus of silane treated jute fiber under RT was higher than that of virgin materials except for 5\% silane concentration. And Young's modulus of silane treated jute fiber under $50^{\circ} \mathrm{C}$ was higher than that of 
virgin materials. But, Young's modulus of silane treated jute fiber under $100^{\circ} \mathrm{C}$ almost did not change. Therefore, it is thought that the tensile property of jute fiber at less than $50^{\circ} \mathrm{C}$ was affected because of fiber surface coupled with silanol group [16].

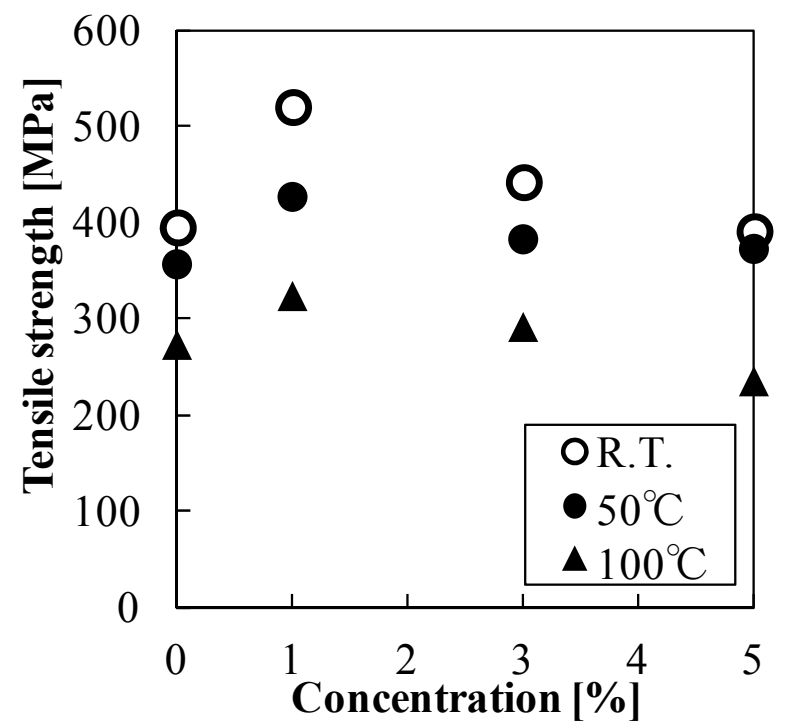

(a) Tensile strength.

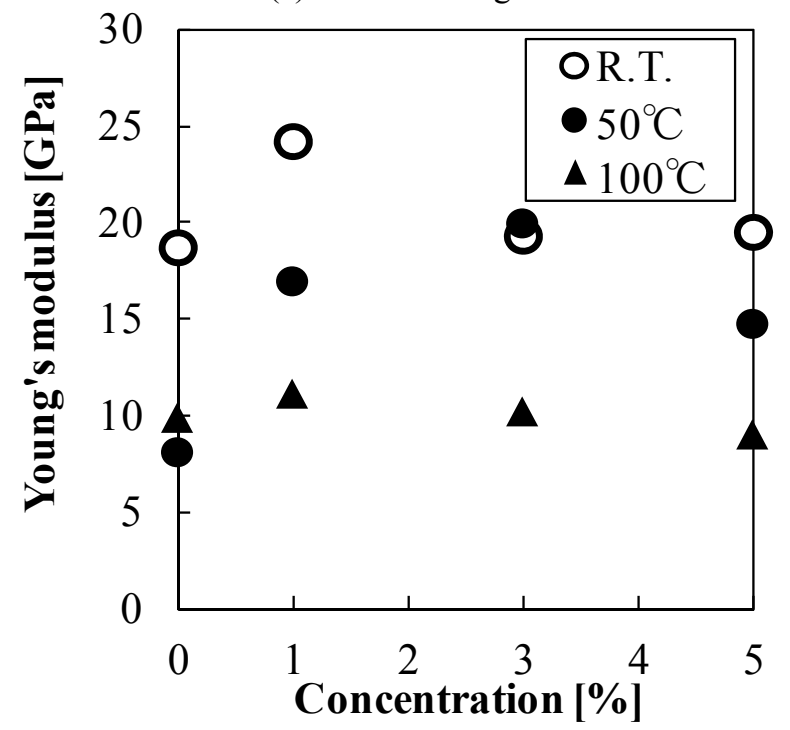

(b) Young's modulus.

Figure 5: Tensile properties of alkaline treated jute fibers. 


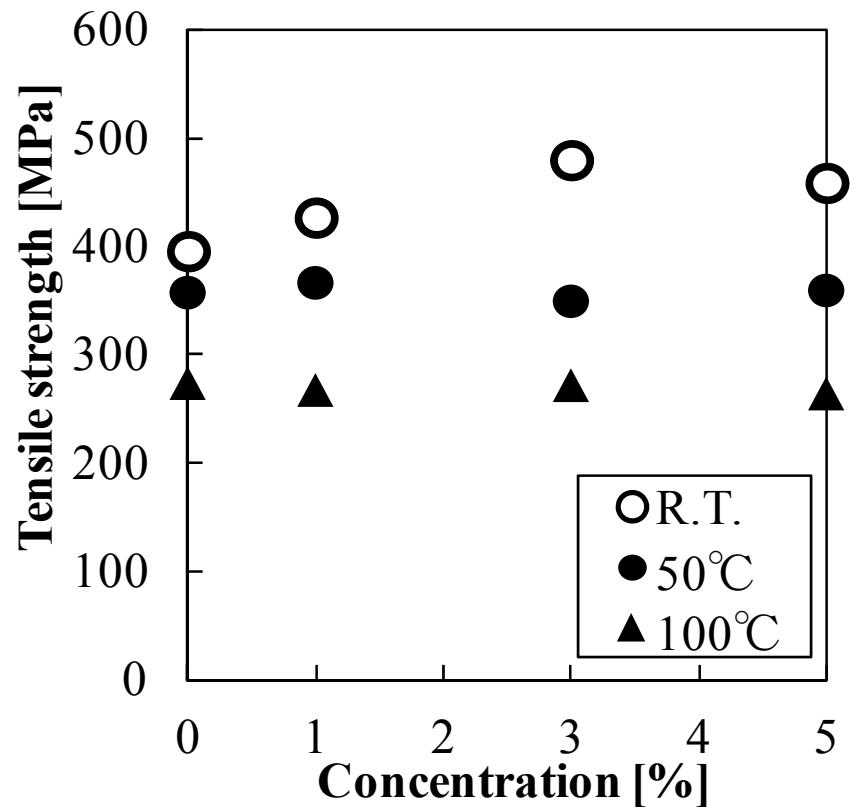

(a) Tensile strength.

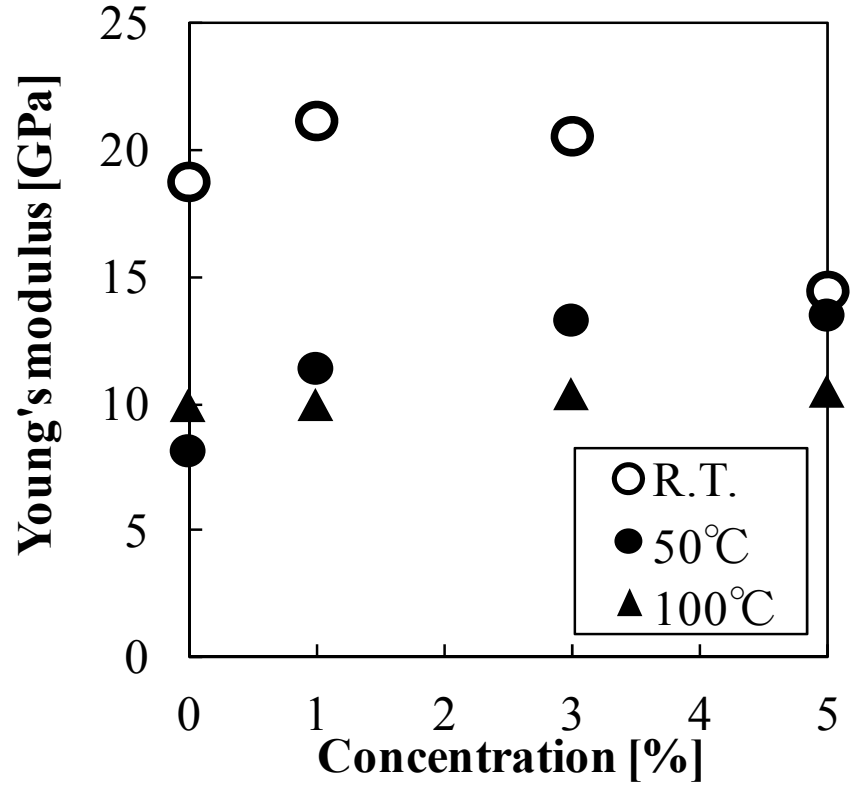

(b)Young's modulus.

Figure 6: Tensile properties of silane treated jute fibers. 


\section{Conclusions}

In this study, the effects of alkaline and silane treatments on the tensile property of jute fiber under environmental temperature were investigated. As a result, the following conclusions are obtained.

1. Coefficient linear expansions of alkaline and silane treated jute fibers were lower than that of virgin material at less than $140^{\circ} \mathrm{C}$. That is, the effect of surface treatments to thermal expansion property is confirmed.

2. Tensile strengths of $1 \%$ alkaline treated jute fiber were higher than those of virgin materials under all environmental temperatures. Among alkaline treated jute fiber, Young's modulus in 1\% concentration was the highest at RT condition. The Young's modulus of alkaline treated jute fiber under $50^{\circ} \mathrm{C}$ was higher than that of virgin material. On the other hand, Young's modulus of alkaline treated jute fiber under $100^{\circ} \mathrm{C}$ almost did not change. In case of alkaline treatment, the rate of cellulose in jute fiber was probably increased by decrease of cross sectional area of jute fiber. Therefore, this rate change of cellulose can affect the tensile property of jute fiber at less than $50^{\circ} \mathrm{C}$ under alkaline treatment condition.

3. Tensile strengths of silane treated jute fiber under RT were higher than that of virgin materials. However, the tensile strength of silane treated jute fiber under $50^{\circ} \mathrm{C}$ and $100^{\circ} \mathrm{C}$ almost did not change. Young's modulus of silane treated jute fiber under RT was higher than that of virgin materials except for 5\% silane concentration. And Young's modulus of silane treated jute fiber under $50^{\circ} \mathrm{C}$ was higher than that of virgin materials. But, Young's modulus of silane treated jute fiber under $100^{\circ} \mathrm{C}$ almost did not change. Therefore, the tensile property of jute fiber at less than $50^{\circ} \mathrm{C}$ was affected by silane treatment because of the coupling silanol group with a surface of jute fibers.

\section{References}

[1] Ben, G., Kihara, Y., Nakamori, K. \& Aoki, Y., Examination of Heat Resistant Tensile Properties and Molding Conditions of Green Composite Composed of Kenaf Fibers and PLA Resin, Advanced Composite Materials, 16, pp. 361-376, 2007.

[2] Katayama, T., Tanaka, K., Murakami, T. \& Uno, K., Compression Moulding of Jute Fabric Reinforced Thermoplastics Composites Based on PLA Non-Woven Fabric, Wit Transactions on The Built Environment, 85, pp. 159-167, 2006.

[3] Katogi, H., Shimamura, Y., Tohgo, K., Fujii, T. \& Takemura, K., Fatigue Behavior of Unidirectional Jute Spun Yarn Reinforced PLA, Advanced Composite Materials, 21, pp. 1-10, 2012.

[4] Takagi, H. \& Asano, A., Effects of Processing Conditions on Flexural Properties of Cellulose Nanofiber Reinforced "Green" Composites, Composites: Part A, 39, pp. 685-689, 2007. 
[5] Takemura, K. \& Minekage, Y., Effect of Molding Condition on Tensile Properties of Hemp Fiber Reinforced Composite, Advanced Composite Materials, 16, pp. 2385-2394, 2007.

[6] Nishino, T., Hirao, K., Kotera, M., Nakamae, K., \& Inagaki, H., Kenaf Reinforced Biodegradable Composite, Composite Science and Technology, 63, pp. 1281-1286, 2003.

[7] Saheb, D. N., \& Jog, J. P., Natural Fiber Polymer Composites: A Review, Advances in Polymer Technology, 18, pp. 351-363, 1999.

[8] Information on http://www.toyota-boshoku.com/jp/news.2009111602.html

[9] Jandas, P. L., Mohanty, S., Nayak, S. K. \& Srivastava, H., Effect of Surface Treatment of Banana Fiber on Mechanical, Thermal, and Biodegradability Properties of PLA/Banana Fiber Biocomposites, Polymer Composites, 32, pp. 1689-1700, 2011.

[10] Yu, T., Ren, J., Li, S., Yuan, H. \& Li, Y., Effect of Fiber SurfaceTreatments on the Properties of Poly(lactic acid)/Ramie Composite, Composites part A, 41, pp. 499-505, 2010.

[11] Gomes, A., Goda, K. \& Ohgi, J., Effects of Alkali Treatment to Reinforcement on Tensile Properties of Curaua Fiber Green Composites, JSME International Journal Series A, 47, pp. 541-546, 2004.

[12] Katogi, H., Takemura, K. \& Miyamoto, S., Effect of Surface Treatment on Flexural Creep Behavior of Plain Woven Jute Fiber Reinforced PLA, Proc. of 9th Int. Conf. Fracture \& Strength of Solid, Jeju, USB (p7), 2013.

[13] Reddy, K. O., Maheswari, C. U., Shukla, M., Song, J. I. \& Rajulu, A. V., Tensile and Structural Characterization of Alkali Treated Borassus Fruit Fine Fibers, Composites: Part B, 44, pp. 433-438, 2013.

[14] Sreekala, M. S., Kumaran, M. G. \& Thomas, S., Oil Palm Fiber: Morphology, Chemical Composition, Surface Modification, and Mechanical Properties, Journal of Applied Polymer Science, 66, pp. 821835, 1997.

[15] Ray, D. \& Sarkar, B. K., Characterization of Alkali-Treated Jute Fibers for Physical and Mechanical Properties, Journal of Applied Polymer Science, 80, pp. 1013-1020, 2001.

[16] Gassan, J., Bledzki, A. K., Effect of Moisture Content on the Properties of Silanized Jute-Epoxy Composites, Polymer Composites, 18, pp. 197-184, 1997. 